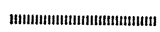 論 文 \\ ESR スペクトロメーターを用いた塗膜の 光劣化に関する評価方法

\author{
岡本 信吾*.正田淳*2
}

\section{Evaluation Method on Photodegradation of Paint Films by Using ESR Spectrometer}

\author{
Shingo Oкамото, Kiyoshi Hrkrta and Hiroaki OHyA-Nishiguchi
}

\section{Synopsis:}

Radicals are generated in paint films by UV-irradiation.

In order to investigate whether bisphenol A/epichlorohydrin type epoxy resin is able to be the radical trapping agent, the clear films prepared as the mixtures of the epoxy resin and polyester/melamine resin were exposed under ultra-high pressure mercury arc lamp (Main wave length, $365 \mathrm{~nm}$ ) at room temperature and the relative concentrations of phenoxyl radical generated were measured by ESR spectrometer.

It was clarified that the epoxy resin was able to be adopted as a suitable radical trapping agent of paint films.

Using the epoxy resin as the radical trapping agent, the relative concentrations of phenoxyl radical for seven clear films, i.e, four kind of silicone modified polyesters (modified quantity; 50\%, 35\%, 20\% and unmodified) and three kinds of acrylic resin, fluoro carbon resin and acrylic resin/fluorocarbon resin were tested with the same method as that mentioned above.

For comparison, gloss retentions and color differences of these paint films were measured after outdoor exposure at Omaezaki, Shizuoka, Japan for 6 to 24 months.

The relative concentrations of the phenoxyl radical estimated by ESR spectrometer, and gloss retentions and color differences of exposed paint films were nicely correlated one another, which shows that the ESR method has a high potential to determine quickly the photodegradation of paint films.

\section{1. 緒}

光, 水, 酸素, 温度は, 塗膜劣化を引き起こす主因子 と考觉られている.

これら 4 つの因子が複雑にからまつて塗膜劣化を促進 させるが，これらの塗膜劣化はすべてラジカルに起因す るため, 塗膜劣化の 解明に ESR (Electron Spin Resonance) スペクトロメーターを用いる方法は有力な手段 となる。

塗膜から生じるラジカルを直接捕捉する方法として, 低温（たとえば液体窒素中では $-196^{\circ} \mathrm{C}$ ) で塗膜に光を 照射し, 生じるラジカルの消隇速度を遅くして捕捉する 方法と, ラジカルトラップ剂を用いて間接的に捕捉する 方法とがある1).

ラジカルトラップ剂としては通常 DMPO (5,5-dimethyl-1-pyrroline-1-oxide)が使用される1)が，極めて
高価な上，熱安定性に欠けるため，高温焼付けが必要な 塗膜のラジカルトラップ剂としては不適である.

$$
\text { ビスフェノールA/エピクロルヒドリン型エポキシ樹 }
$$
脂は, 光照射によつて室温でも安定なフェノキシルラジ カル $(\mathrm{R} \cdot$ と略す）を生じる2) 上に，塗料に使用される ほとんどの樹脂と良い相溶性を示し，実際にコイルコー ティングのプライマーに，また家電用途のポリエステル 塗料やアクリル塗料中に数パーセント混入して, 素材と の付着性を高めるために使用されている.

$$
\text { このため, オイルフリーポリエステル樹脂/アミノ樹 }
$$
脂塗料に, このタイプのエポキシ樹脂を混入して, エポ キシ樹脂が 塗膜のラジカルトラップ剂として使用でき るかどらかをESR スペクトロメーターを用いて検討し た.

次に，エポキシ樹脂をラジカルトラップ剂として用い て，耐候性の良好なシリコン変性度の異なる 4 種類のポ

昭和 60 年 10 月 28 日受付 (Received Oct. 28, 1985)

* 日本油脂(株) 戸塚工場 (Totsuka Factory, Nippon Oil \& Fats Co., Ltd., 296 Shimokurata-cho Totsuka-ku Yokohama 244)

*2 日本油脂(株)筑波研究所 (Tsukuba Research Lab., Nippon Oil \& Fats Co., Ltd.)

*3 京都大学理学部 理博 (Faculty of Science, Kyoto University) 
リエステル塗料（シリコン変性度，50\%，35\%，20\% と Unmodified) と,アクリル樹脂, ふつ素樹脂および アクリル樹脂とふつ素樹脂の混合樹脂の 3 種類とについ て，それぞれのクリヤ一塗膜に紫外線を照射して生じる フェノキシルラジカル濃度 $(C(\mathrm{R} \cdot)$ と略す $)$ を $\mathrm{ERR}$ ス ベクトロメーターを用いて測定した。

さらに，これらの樹脂を用いて白エナメル塗料を作成 乙, 御前崎にて 2 年間の屋外暴露を行い, 光沢保持率と 色差とを求め, $C(\mathrm{R} \cdot)$ との相関性について検討した.

\section{2. 実 験 方 法}

\section{$2 \cdot 1$ 試 料}

本実験に供した樹脂，顔料は次のとおりである。

（1）シリコン変性ポリエステル樹脂

グリセリン，トリメチロールプロパン，イソフタル酸, アジピン酸，取心性シリコン樹脂を縮重合させシリコン 変性度の巽なる 4 種類のポリエステル樹脂 $\mathrm{R}-1 \sim \mathrm{R}-4$ を得た。粘度は $T \sim X$, 酸価 6〜10 であつた。 $\mathrm{R}-1: 50 \%$ silicone modified polyester, $60 \%$ soln. $\mathrm{R}-2$ : $35 \%$ silicone modified polyester, $60 \%$ soln. $\mathrm{R}-3: 20 \%$ silicone modified polyester, $60 \%$ soln. R-4 : Oil free polyester, $60 \%$ soln.

（2）アクリル樹脂

メチルメタアクリレート，ブチルアクリレート，ヒドロ キシメタアクリレートを溶液重合させ， R-5 を得た.

$\mathrm{R}-5$ : Acrylic resin, 50\% soln. $(\mathrm{M} \bar{n}=6400, \mathrm{OH}$ value 50)

(3) ふつ素樹脂

R-6 : 旭硝子(株)のルミフロン LF-200, 50\% soln.

(4) アミノ樹脂

H-1：ブチル化メラミン樹脂, $60 \%$ soln.

(MST : 6〜9, Viscosity : $\mathrm{H} \sim \mathrm{O})$

(5) イソシアネート

H-2 : ヘキサメチレンジイソシアネート 3 量体

(6) エポキシ樹脂

油化シェル(株)のエピコート $¥ 1001,60 \%$ soln.

(7) 二酸化チタン

帝国化工(株)の JR-602

\section{$2 \cdot 2$ 染料の調整}

上記試料を用いて，Table 1 に示したクリヤー塗料 P-1〜P-10 は, 樹脂/硬化剂 100 重量部に対してエポキ シ樹脂をそれぞれ精科して加え，スリーワンモーターで 靦拌して得た。

また, Table 2 に示した白エナメル塗料 P-11〜P-17 は顔料として二酸化チタンを用い, 顔料/バインダーの
Table 1. Formula of clear paints.

\begin{tabular}{|c|c|c|c|c|c|c|c|c|c|c|}
\hline & & & & & & & & \multicolumn{3}{|c|}{ Parts by weight } \\
\hline \multirow{2}{*}{ Constituents } & \multicolumn{10}{|c|}{ Paint No. } \\
\hline & $\mathrm{P}-1$ & $\mathrm{P}-2 \mid$ & $\mathrm{P}-3$ & $\mathrm{P}-4$ & $P-5$ & $P-6$ & $\mathrm{P}-7$ & $\mathrm{P}-8$ & $P-9$ & $\mathrm{P}-10$ \\
\hline$R-1^{1)}$ & & & & & 70 & & & & & \\
\hline $\left.\mathrm{R}-2^{2}\right)$ & & & & & & 70 & & & & \\
\hline$R-3^{3)}$ & & & & & & & 70 & & & \\
\hline$\left.R-4^{4}\right)$ & 70 & 70 & 70 & 70 & & & & & & \\
\hline$R-5^{5)}$ & & & & & & & & 64 & 32 & \\
\hline$\left.R-6^{6}\right)$ & & & & & & & & & 32 & 64 \\
\hline $\mathrm{H}-1^{7)}$ & 30 & 30 & 30 & 30 & 30 & 30 & 30 & & & \\
\hline $\mathrm{H}-2^{8)}$ & & & & & & & & 36 & 36 & 36 \\
\hline Epoxy resin $\left.{ }^{9}\right)$ & & 5 & 10 & 20 & 5 & 5 & 5 & 5 & 5 & 5 \\
\hline $\begin{array}{l}\text { 1) } 50 \% \text { silicc } \\
\text { 2) } 35 \% \text { silice } \\
\text { 3) } 20 \% \text { silice } \\
\text { 4) Oil free p } \\
\text { 5) Acrylic r } \\
\text { 6) Fluorocar } \\
\text { 7) Butylated } \\
\text { 8) Trimer of } \\
\text { 9) Bispheno }\end{array}$ & $\begin{array}{l}\text { ne } \mathrm{m} \\
\text { ne } \mathrm{m} \\
\text { ne } \mathrm{m} \\
\text { olyes } \\
\text { sin, } \\
\text { bon } \\
\text { mela } \\
\text { HDI } \\
\text { A }\end{array}$ & $\begin{array}{l}\text { hodifi } \\
\text { hodifi } \\
\text { hodifi } \\
\text { ter, } 6 \\
50 \% \\
\text { resin, } \\
\text { mine } \\
\text { [, } 30 \% \\
\text { pichl }\end{array}$ & $\begin{array}{l}\text { ed } \\
0 \% \\
\text { soln. } \\
50 \% \\
\text { resi } \\
\text { oro sol } \\
\text { oro }\end{array}$ & $\begin{array}{l}\text { olyes } \\
\text { olyes } \\
\text { olyes } \\
\text { soln. } \\
\text { soln } \\
\text { n, } 60 \\
\text { ln. } \\
\text { hydri }\end{array}$ & $\begin{array}{l}\text { ter. } 6 \\
\text { ter. } 6 \\
\text { ter. } 6 \\
\% \text { so }\end{array}$ & $\begin{array}{l}30 \% \\
50 \% \\
0 \%\end{array}$ & $\begin{array}{l}\text { soln. } \\
\text { soln. } \\
\text { soln. }\end{array}$ & & & \\
\hline
\end{tabular}

Table 2. Formula of pigmented paints.

\begin{tabular}{c|c|c|c|c|c|c|c}
\hline \multicolumn{1}{c|}{} & \multicolumn{7}{c}{ Paint No. } \\
\hline & Constituents by weight \\
\hline & P-11 & P-12 & P-13 & P-14 & P-15 & P-16 & P-17 \\
\hline R-1 & 41.0 & & & & & & \\
\hline R-2 & & 41.0 & & & & & \\
\hline R-3 & & & 41.0 & & & & \\
\hline R-4 & & & & 41.0 & & & \\
\hline R-5 & & & & & 47.0 & 23.5 & \\
\hline R-6 & & & & & & 23.5 & 47.0 \\
\hline H-1 & 17.5 & 17.5 & 17.5 & 17.5 & & & \\
\hline H-2 & & & & & 15.0 & 15.0 & 15.0 \\
\hline Pigment ${ }^{11}$ & 31.5 & 31.5 & 31.5 & 31.5 & 28.0 & 28.0 & 28.0 \\
\hline Solvent & 10.0 & 10.0 & 10.0 & 10.0 & 10.0 & 10.0 & 10.0 \\
\hline Total & 100 & 100 & 100 & 100 & 100 & 100 & 100 \\
\hline
\end{tabular}

1) Titanium dioxide, weather resistance grade

固形分重量比を 0.9 とし，つぶゲージで $10 \mu \mathrm{m}$ 以下に なるまでペイントコンディショナーで分散して得た.

\section{$2 \cdot 3$ ESR 測定}

ESR 装置は, JEOL, JM-FE-3X (日本電子(株)）を 用いた。

クリヤー塗料 $\mathrm{P}-1 \sim \mathrm{P}-7$ を X-Band 用 $\mathrm{ESR}$ 試料管 (日電子技術サービス(株)）の外側に底から $5 \mathrm{~cm}$ の高 さに浸漬塗装し, セッティング $10 \mathrm{~min}$ 後に, 熱風乾燥 炉で, $150^{\circ} \mathrm{C}, 20 \mathrm{~min}$ 焼付け, 平均乾燥塗膜厚 $50 \mu \mathrm{m}$ の FP-1〜FP-7 の塗膜を得た.

同様の方法でクリヤー塗料 P-8〜P-10 から FP-8～ FP-10 の塗膜を得た. 


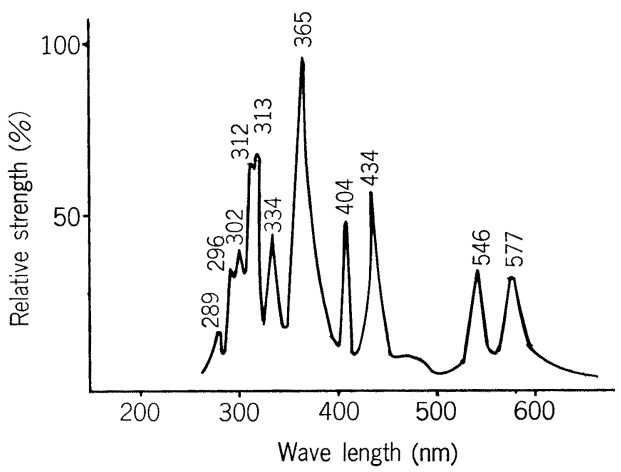

Fig. 1. Wave length of ultra-high pressure mercury arc lamp.

これらの塗膜に, Fig. 1 に示す波長分布を有する高圧 水銀ランプ, USH-500 D (ウシオ電気(株))を用いて紫 外線を照射し（UV 照射と略す）一定時間ごとに生じた $C(\mathrm{R} \cdot)$ を測定した。

測定は室温で行い，標準試料として酸化マグネシウム の中にらめ込んだ $\mathrm{Cr}^{+3}$ を用いた。

\section{$2 \cdot 4$ 光沢保持率および色差の測定}

光沢度は Gloss Meter Model TG-108D (Tokyo Denshoku Co., Ltd.) を用い, 60 度鏡面光沢度を測定 した.

色差は SM カラーュンピューターSM-1 形色差計(ス ガ試験機(株)）を用い, Hunter 色差 $(\Delta E)$ を測定し た.

塗料 P-11〜P-14 を塗料粘度 $90 \mathrm{~s}$ (Ford cup \#4, 25 $\left.{ }^{\circ} \mathrm{G}\right)$ になるようにキシレンで調整して，プライマー塗装 した亚鉛めつき鋼板 $(0.8 \times 100 \times 200 \mathrm{~mm})$ 上にバーコ ーターを用いて塗装し, セッティング $10 \mathrm{~min}$ 後に熱風 乾燥炉で $150^{\circ} \mathrm{C}, 20 \mathrm{~min}$ 焼付け, 乾燥塗膜厚 $50 \mu \mathrm{m}$ の 塗板（TP-11〜 TP-14）を得た.

また同様の方法で, 塗料 $\mathrm{P}-15 \sim \mathrm{P}-17$ を塗装し, セッ ティング $10 \mathrm{~min}$ 後に熱風乾燥炉で $80^{\circ} \mathrm{C}, 30 \mathrm{~min}$ 乾燥 乙乾燥塗膜厚 $30 \mu \mathrm{m}$ の塗板（TP-15〜 TP-17）を得た. これら塗板を御前崎にて, 南面 $30^{\circ}$ で屋外菛露試験を 行い,一定時間ごとに光沢度と色差 $(\Delta E)$ を測定した。

\section{3. 結果および考察}

\section{1 ラジカルトラップ風としてのエポキシ樹脂}

試料 FP-1〜FP-4 に打いて, UV 照射前と照射後一 定時間照射した後に ESR スペクトルの測定を行つた.

試料 FP-2 FP-4 は，同様の ESR スペクトルを与 えた. 試料 FP-2 の ESR スペクトルを Fig. 2 に示し
1)

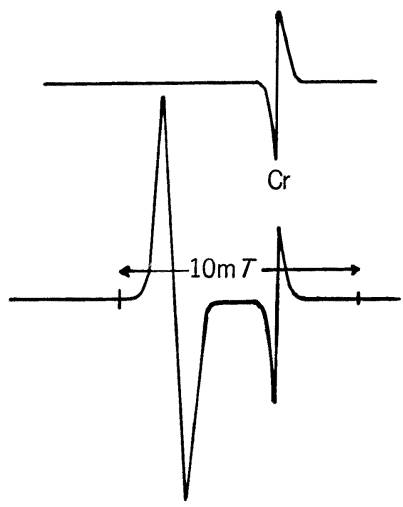

Notc 1) State without irradiation

2) State with irradiation

Fig. 2. ESR charts of UV irradiated FP-2 film.

Table 3. Relative concentration of phenoxyl radical caused by UV irradiation.

\begin{tabular}{c|c|c|c|c}
\hline \multirow{2}{*}{$\begin{array}{c}\text { Irradiation } \\
\text { time, min }\end{array}$} & \multicolumn{4}{|c}{ Relative concentration } \\
\cline { 2 - 5 } & $\mathrm{FP}-1$ & $\mathrm{FP}-2$ & $\mathrm{FP}-3$ & $\mathrm{FP}-4$ \\
\hline 0 & 0 & 0 & 0 & 0 \\
2.5 & 0 & 2.3 & 3.0 & 4.5 \\
5.0 & 0 & 3.6 & 4.8 & 6.9 \\
7.5 & 0 & 4.5 & 5.8 & 8.8 \\
10.0 & 0 & 5.2 & 7.0 & 10.2 \\
12.5 & 0 & 6.0 & 7.8 & 11.3 \\
15.0 & 0 & 6.5 & 8.6 & 12.3 \\
17.5 & 0 & 7.0 & 9.2 & 13.2 \\
20.0 & 0 & 7.5 & 9.6 & 13.9 \\
\hline
\end{tabular}

たがマーカーの $\mathrm{Cr}^{+3}$ ピーク以外の大きなピークは $g=$ 2.0042 より $\mathrm{R}$. と阔定した。

武料 FP-1 からは紫外線照射によつて R・はみいだ せなかつた。

ESR 測定装监の増幅度の変化, キャビティー特性の 変化，温度変化を除くため，生じた R・のピーク高さ を, マーカーの闹さで别つた相対フェノキシルラジカル 濃度 $\left(C^{\prime}(\mathrm{R} \cdot)\right.$ と略す) を求めて Table 3, Fig. 3 亿示 した．塗膜中に含まれるェポキシ樹脂が增加すると， $C^{\prime}$ (R・) も增加した.

試料 FP-2 FP-4 において生じた $C(\mathrm{R} \cdot)$ は, 式 （1）よりエポキシ樹脂が们接光エネルギーを受けて生じ た $C(\mathrm{R} \cdot)$ と, 光照射によつてバインダ一から生じた不 安定ラジカル $(\mathrm{B} \cdot$, 式 $(2))$ がエネルギー $A \cdot E$ を失つ て, もとの化合物 (B) か新しい化合物 $\left(\mathrm{B}^{\prime}\right)$ に変化し(式 $(3))$ ，エネルギー $A \cdot E$ を受け取つて生じる $C(\mathrm{~B} \cdot)$ （式 (4)）との和になると考觉られる. 


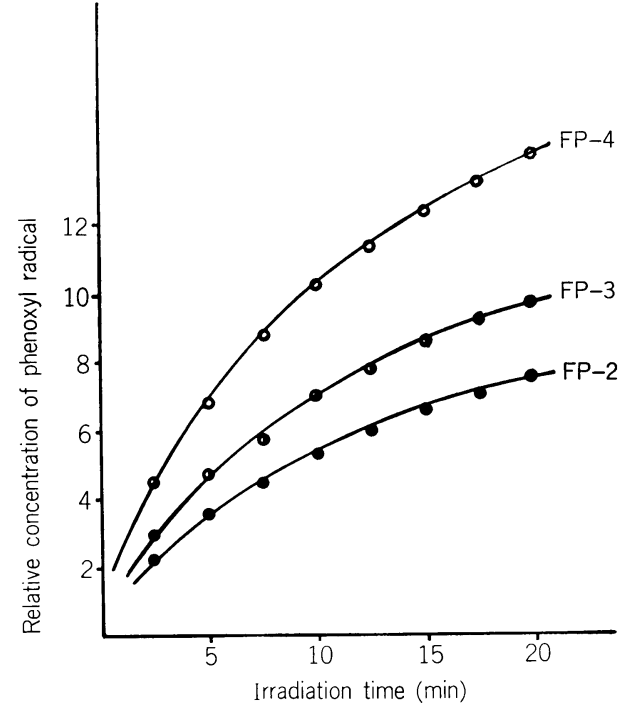

Fig. 3. Relative concentration of phenoxyl radical vs irradiation time on FP-2 FP-4 coatings caused by UV irradiation.

Epoxy resin $\stackrel{h \nu}{\longrightarrow} \mathrm{R}$

Binder $\stackrel{h \nu}{\longrightarrow} \mathrm{B}$.

$\mathrm{B} \cdot \longrightarrow \mathrm{B}^{\prime}($ or $\mathrm{B})+A \cdot E$

Epoxy resin $+A \cdot E \longrightarrow C^{\prime}(\mathrm{R} \cdot)$

このため Fig. 3 に亦した $C^{\prime}(\mathrm{R} \cdot)$ はエポキシ樹脂か ら生じた $C^{\prime}(\mathrm{R} \cdot)$ と, オイルフリーポリエステル樹脂/ アミノ樹脂のバインダー樹脂から生じたラジカル濃度 $C^{\prime}(\mathrm{B} \cdot)$ との和になると考えてよい.

陚料 FP-3 から生じた $C^{\prime}(\mathrm{R} \cdot)$ から FP-2 のそれを 差し引き，この差を $x_{1}$ とし，他才j FP-2の $C^{\prime}(\mathrm{R} \cdot)$ か らこの $x_{1}$ を差し引いた值はバインダー樹脂から生じた $C_{1}{ }^{\prime}(\mathrm{B} \cdot)$ に相当する.

また試料 FP-4 から生じた $C^{\prime}(\mathrm{R} \cdot)$ から FP-3 のそ れを差し引きこの差を $x_{2}$ とし， FP-3の $C^{\prime}(\mathrm{R} \cdot)$ から $x_{2}$ を差し引いた值も同様にバインダー樹脂から生じた $C_{2}{ }^{\prime}(\mathrm{B} \cdot)$ に相当する.

$C_{1}{ }^{\prime}(\mathrm{B} \cdot)$ と $C_{2}{ }^{\prime}(\mathrm{B} \cdot)$ の任を Table 4 , Fig. 4 に示し た. Fig. 4 に示されるよらに， $C_{1}{ }^{\prime}(\mathrm{B} \cdot)$ と $C_{2}{ }^{\prime}{ }{ }^{(\mathrm{B} \cdot)}$ は 誤差の範囲付で一・致した。ここで $x_{1}, x_{2}$ はエポキシ添 加量増加による生成 ラジカルの增加量を表しており, 従つて式(1)によるラジカル生成と考えてよい. 他方 $C_{1}{ }^{\prime}(\mathrm{B} \cdot), C_{2}{ }^{\prime}(\mathrm{B} \cdot)$ は添加量に無関係のラジカル生成量 であるから式 (3)，（4)に従5 R・ 生成量に対応する。 以上のことからェポキシ樹脂は, 塗膜としてのラジカ
Table 4. Relative concentration of phenoxyl radical appeared on binder resins, for the value calculated on FP-2 and FP-3 (A) and on $\mathrm{FP}-3$ and $\mathrm{FP}-4$ (B).

\begin{tabular}{c|c|c}
\hline \multirow{2}{*}{$\begin{array}{c}\text { Irradiation } \\
\text { time, min }\end{array}$} & \multicolumn{2}{|c}{$\begin{array}{c}\text { Relative concentration of } \\
\text { phenoxyl radical }\end{array}$} \\
\cline { 2 - 3 } & $\mathrm{A}$ & $\mathrm{B}$ \\
\hline 0 & 0 & 0 \\
\hline 2.5 & 1.56 & 1.54 \\
\hline 5.0 & 2.29 & 2.72 \\
\hline 7.5 & 3.11 & 2.86 \\
\hline 10.0 & 3.42 & 3.80 \\
\hline 12.5 & 4.10 & 4.38 \\
\hline 15.0 & 4.41 & 4.80 \\
\hline 17.5 & 4.83 & 5.18 \\
\hline 20.0 & 5.44 & 5.22 \\
\hline
\end{tabular}

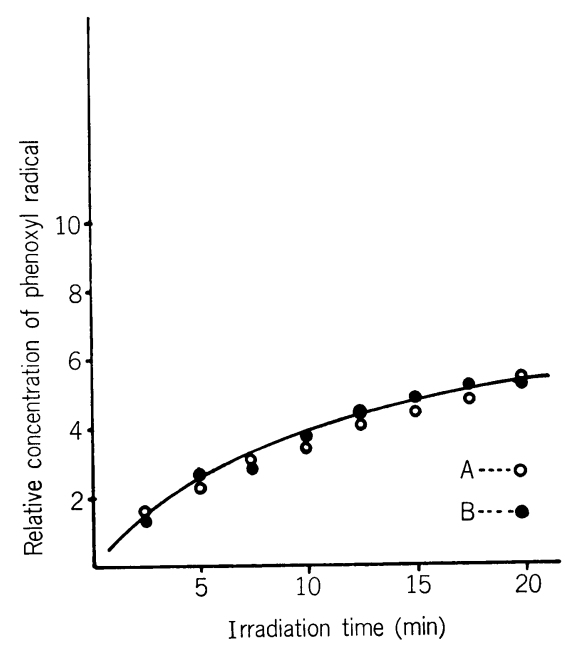

Fig. 4. Relative concentration of phenoxyl radical vs irradiation time, for the value calculated on FP-2 and FP-3 (A-.O) and on FP-3 and FP-4

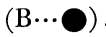

ルトラップ剂として使用できることが見いだされた。

\subsection{ESR スペクトロメーターを用いた耐候性評価方法}

シリコン変性度の異なるポリエステル樹脂系試料 FP-2, FP-5〜 FP-7 と, アクリル樹脂，フッ素樹脂およ びアクリル樹脂と ふつ素樹脂の 混合樹脂試料 FP-8 FP-10 とにおいて，照射時間ごとに生じた $C^{\prime}(\mathrm{R} \cdot)$ を Fig. 5, Fig. 6 に示した.

Fig. 5, Fig. 6 より 5 min 照射した後には, 生じた $C^{\prime}(\mathrm{R} \cdot)$ 間に差を生じ， $C^{\prime}(\mathrm{R} \cdot)$ は $20 \mathrm{~min}$ 照射までそ の順位を変えることなく増加し，乙か子塗膜の材質に対 応した増加量を示すことに興味が持たれる. 


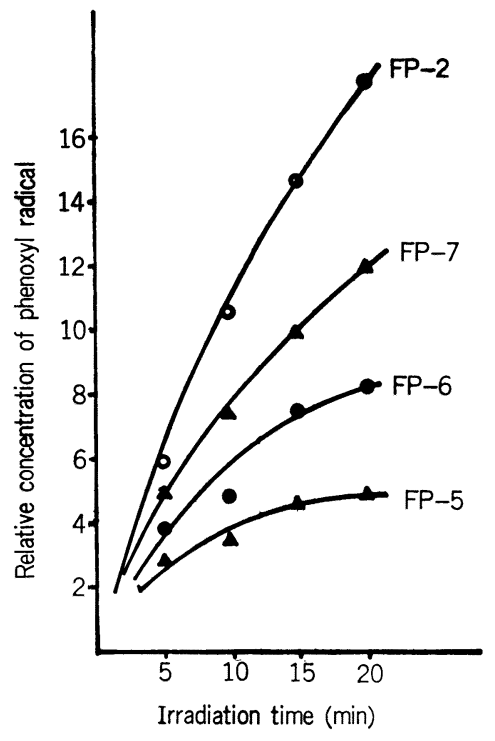

Fig. 5. Relative concentration of phenoxyl radical vs irradiation time on FP-2 and FP-5 FP-7 coatings.

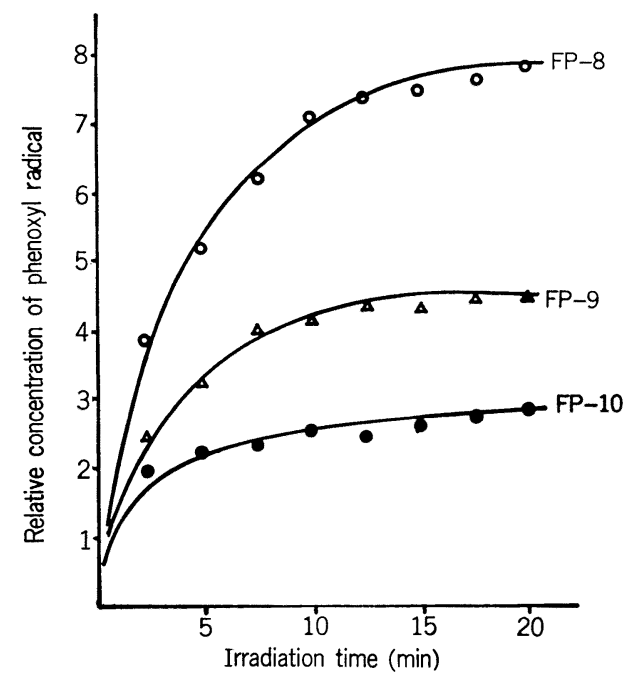

Fig. 6. Relative concentration of phenoxyl radical vs irradiation time on $\mathrm{FP}-8 \sim \mathrm{FP}-10$ coatings.

まず第一に，Fig. 5 よりシリコン変性度の高いクリ ヤー塗膜ほど生じるラジカル量が低下することである.

これはシリコン変性塗膜の耐候性と反比例の関係にある ことが予想される.

また Fig. 6 よりアクリル樹脂，ふつ素樹脂特よびア クリル樹脂とふつ素樹脂の混合樹脂系塗膜において，ふ つ素樹脂の 含有量が多いものほど, 生じるラジカル量

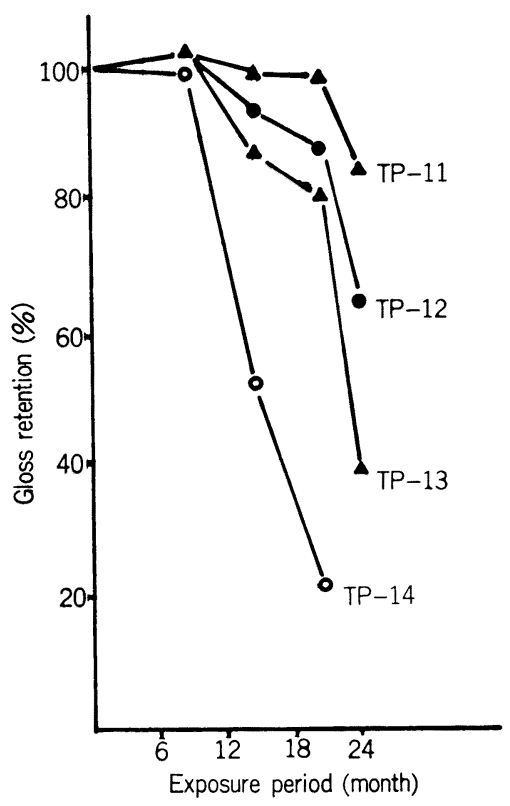

Note : Initial gloss TP-11:93, TP-12:91, TP-13:90, TP-14: 92

Fig. 7. Outdoor exposure test on $\mathrm{TP}-11 \sim \mathrm{TP}-14$ coatings at Omaezaki Shizuoka prefecture, $30^{\circ} \mathrm{S}$.

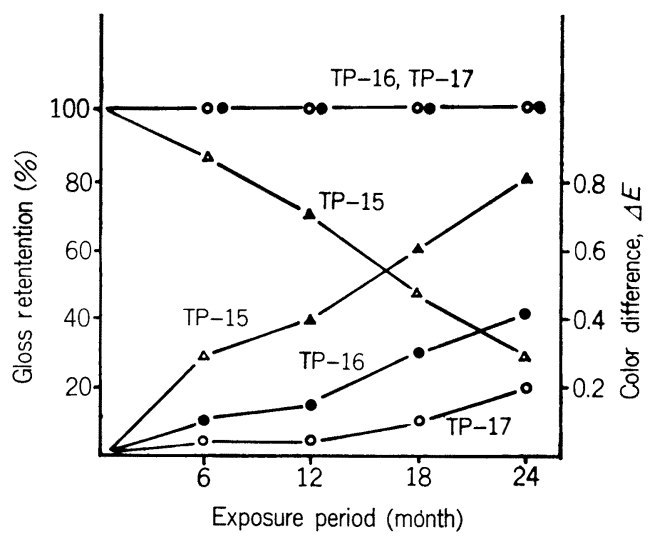

Note : Initial gloss

TP-15:85, TP-16:83, TP-17: 82

Fig. 8. Outdoor exposure test on TP-15, TP-16 and TP-17 coatings at Omaezaki, Shizuoka prefecture, $30^{\circ} \mathrm{S}$.

$C^{\prime}(\mathrm{R} \cdot)$ は低かつた。すなわち耐候性の良い塗膜ほどラ ジカル生成量が少ないといら経験則がこの結果で裏付け されたことになる。

これらの結果から第二にシジカルトラップ剂として用 いるェポキシ樹脂星は固形分として，バインダー樹脂 100 部に対して 5 部加えれば耐候性芸験の尺度としての 
役割を果たすといえる。

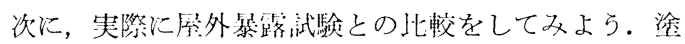
板 TP-11 TP-17 の初期 $60^{\circ}$ 光沈と, 御前崎南面 $30^{\circ}$

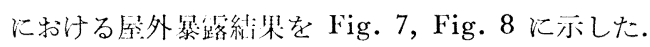

Fig. 7 より, シリコン变性度の活い樹脂を用いたエ ナメル塗膜ほど光沈保持摔が满かつた.

Fig. 8 より，アクリル樹脂，ふつ䒺樹脂およびアクリ

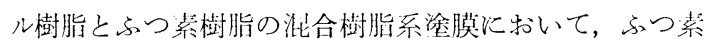
樹脂系塗膜と，泥合樹脂系涂膜とでは，光沢保持㳯には 差を生じないが，混合樹脂系涂膜の才が色差: $(\Delta E)$ は大 きかつた。

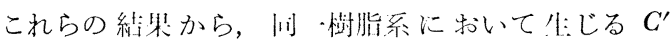

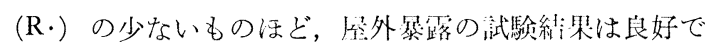
あつた。これらの絬果より， ESR スベクトロメーター
が，焼付形塗料，常乾形叙料とともに極めて短時間で済 屯塗膜の光劣化特性の評俩方法として十分使用できる可 能性を示唆している，従来屋外暴露試験あるいはサンシ ナインウェザーメーターなどの促進耐候性試験という長 時阔を要する試験法に代わつて， ESR スペクトロメー ターによる塗膜内生成ラジカル是測定法は今後有力な耐 候性試験法になるものと期待している.

本研究に際し，御指導いただきまた京都大学，理学 部化学教至, 広由 裹教授に感勆いたします。

\section{文献}

1) E. $M$. Ceresa, L. Burlamagchi and $M$. Visca: J. Mater. Sci. 18 (1983), p. 289

2) 正田 淳, 网本信吾, 大矢博昭: 色材, 57 (1984) 2, p. 51 